\title{
PERIGOS E MEDOS NAS CANTIGAS DE SANTA MARIA. DO MAR E DOS SEUS TORMENTOS*
}

\author{
Déborah GonZÁLEZ \\ deborah.gonzalez@usc.es \\ Universidade de Santiago de Compostela
}

La búsqueda de las maravillas constituye uno de los más importantes atractivos de la exploración del mundo.

C. Kappler

\section{O HOMO VIATOR NA SOCIEDADE MEDIEVAL}

Desde as súas orixes, a humanidade precisou desprazarse por causas diversas (conquista de territorios, comercio, supervivencia, devoción, etc.), procurando novos camiños, construíndo pontes e vías polas que conducirse e manterse conectado, nun constante proceso de cambio e progreso. Durante o período medieval, a itinerancia de pobos e de individuos foi de grande trascendencia para a expansión e desenvolvemento da sociedade. As razóns para emprender a marcha podían ser diversas e múltiples, aínda que as fundamentais serían de índole política, bélica, económica e relixiosa. Toda viaxe podía implicar outras consecuencias e beneficios engadidos para o individuo e a colectividade, xa que era un medio para establecer comunicacións, intercambiar ideas e obxectos, dar a coñecer obras e textos (os cales podían seguir un itinerario de ida e volta polas vías que atravesaban o occidente cristián e que mesmo podían prolongarse máis alá).

Ademais, como explicaba Claude Kappler ${ }^{1}$, a ruptura do estatismo e da separación inicial enxendraría unha aventura que podía dar froitos positivos, porque, malia o risco que supuña abandonar o seguro polo descoñecido, brindaba ao viaxeiro a posibilidade de evolucionar e adquirir un coñecemento superior de si mesmo e do mundo que o rodeaba. De tal maneira, como «experiencia iniciática», a travesía non estaba exenta dunha compoñente espiritual, de renovación e de procura, en vista da transformación que se experimentaba ata chegar á meta ou á obtención daquilo que se ansiaba. Certo é que o viaxeiro

*O presente traballo asóciase ao proxecto posdoutoral Estudo léxico-semántico das Cantigas de Santa Maria: as emocións (I2C - Xunta de Galicia).

${ }^{1}$ Claude Klapper, Monstruos, demonios y maravillas afines de la Edad Media, Madrid, Akal, 1986, p. 88 
medieval podía informarse e anticiparse aos múltiples riscos e perigos que, tanto de índole física como espiritual, podían atravesarse no seu camiño. Faríao a través de noticias e textos de distintas naturezas: desde guías destinadas a peregrinos, mercaderes ou viaxeiros, ata relatos literarios onde se podían combinar en diferente medida o realista e o fantástico.

\section{As rotas nas CantigaS de SANTa Maria}

Segundo Kappler, as marabillas eran o tema central de todos os libros de viaxes ${ }^{2}$. Pero o extraordinario non só ocuparía un lugar preferente neste tipo de produción literaria medieval: o marabilloso -aínda que doutro tipo- é, así mesmo, o elemento esencial das coleccións de milagres, como as Cantigas de Santa Maria de Alfonso $\mathrm{X}$. Ademais, nesta obra, o extraordinario e o milagroso xorden moi a miúdo no transcurso de viaxes que, por distintas motivacións, emprenden personaxes de distintas clases sociais. $\mathrm{O}$ afán por plasmar dun modo realista a sociedade na súa multiplicidade favorecería a inclusión de narracións que aluden e retratan o vagar e a itinerancia característicos de distintos grupos sociais, e isto acontecería tanto na dimensión textual das Cantigas como na vertente iconográfica. Máis concretamente sobre a miniatura dos códices $T$ e $F$, manifestaba Victoria Chico $\mathrm{Picaza}^{3}$ que a vontade de representar un mundo diverso conduciría á necesidade de confeccionar un sistema gráfico que puidese proporcionar realismo, orde e coherencia á representación e, segundo a referida investigadora, tal sistema baseouse principalmente na plasmación dun constante movemento dos personaxes retratados, concluíndo que: «Cuando el scritorium alfonsí necesitó plasmar con realismo la vida palpitante del siglo XIII castellano a través de estas miniaturas, esta vida debía quedar plasmada del modo en que la sentían, como un viaje» ${ }^{4}$.

Consecuente con esa diversidade, o viaxeiro das Cantigas non obedece a un único tipo social: viaxaban reis, raíñas, monxes, xograres, exércitos, damas, mercadores, cabaleiros, peregrinos... e, ás veces, mudándose ou superpoñéndose estes distintos perfís. Con todo,

${ }^{2}$ «Las maravillas son el gran tema de todos los libros de viajes. La relación de Joudain de Séverac lleva sencillamente el título de Mirabilia, algo muy habitual en la Edad Media. La primera página es paradigmática, y comienza así: "Inter Siciliam autem et Calabriam est unum mirabile in mari". Cuatro líneas después: "fit una revolutio mirabilis". Ocho líneas más abajo: "et hoc est mirabile valde". Diez más: "mirabile magnum etian". Abundan exclamaciones como Mirabile!, Mirares!, Mirae admirationis; son muy frecuentes las expresiones del tipo "maravillarse", "deben maravillarse". Su sentido sigue siendo el del verbo latino mirari, que indica admiración, sorpresa, gusto por lo nuevo y extraordinario, no por lo bello». Claude Kappler, Monstruos..., op. cit., pp. 55-56.

${ }^{3}$ María Victoria Chico Picaza, «La vida como un viaje: viaje y peregrinación en la composición pictórica de las Cantigas de Santa María de Alfonso X el Sabio», Revista de Filología Románica. Anejo IV (2006), pp. 129-133.

${ }^{4}$ María Victoria Chico Picaza, «La vida como un viaje...», art. cit., p. 133. 
nunha colección desta natureza, que exalta a figura de María e promociona a súa devoción, a viaxe de maior trascendencia é a peregrinación $^{5}$, entendida en sentido amplo como visita a un santuario con fin devocional ${ }^{6}$. En múltiples narracións o milagre realízase a favor de personaxes que se encontran no transcurso dunha peregrinatio e, en moitas outras, tras o beneficio dunha intervención mariana, conclúese coa visita a un local dedicado a María para dar as merecidas grazas (polo que o milagre tamén adoita ser causa desencadenante dunha viaxe). Na colección, son recorrentes as expresións romeu, romeiro, romería e romaría, e os lugares de veneración mencionados son múltiples: desde os célebres Xerusalén, Roma e Santiago, ata os especificamente consagrados á Virxe e que salpican toda a xeografía da Europa medieval (Terena, Tudia, Salas, Vila-Sirga, Montserrat, París, Soisson, Rocamador e un longo etc.). A miúdo, esas igrexas serían visitadas por aqueles que residían nas proximidades, encomendados nunha promesa á Virxe do lugar ou atraídos pola sona dos marabillosos favores outorgados a outros, mesmo testemuñándose o hábito de visitar periodicamente un santuario ${ }^{7}$, definíndose a peregrinación como un auténtico "fenómeno de masas", como a caracterizou Rubio Tovar ${ }^{8}$. Fronte ao que acontece noutras fontes medievais, onde se utilizaron distintos termos para referirse aos que se dirixían aos principais destinos de devoción, nas Cantigas de Santa Maria empregáronse unicamente romeiro e romeu para os distintos tipos de peregrino9. Segundo Daniel Grégorio, isto podería gardar relación

\footnotetext{
${ }^{5}$ Sobre a peregrinación e os peregrinos nas Cantigas de Santa Maria, poden consultarse os traballos de: María Victoria Chico Picaza, «Life, Pilgrimage and Women in Alfonso X's Cantigas de Santa Maria», en C. A. González-Paz (ed.), Women and Pilgrimage in Medieval Galicia, Burlington, Ashgate, 2015, pp. 145-153; Elvira Fidalgo, «Peregrinos en las Cantigas de Santa Maria», en S. López Martínez-Morás et alii (eds.), Identidad europea e intercambios culturales en el Camino de Santiago (siglos XI- XV), Santiago de Compostela, Universidade de Santiago de Compostela, 2013, pp. 207-223; Daniel Grégorio, «Pèlerinages et chemin initiatique dans les Cantigas de Santa Maria», Cahiers d'études hispaniques médiévales, 30 (2007), pp. 127-144; Jeanne Raimond, «Les femmes en chemin dans les Cantigas de Santa Maria», Cahiers d'études hispaniques médiévales, 30 (2007), pp. 67-82.

${ }^{6}$ Lembraremos a coñecida e tantas veces repetida explicación que se recolle no libro Primeiro das Siete Partidas (Alfonso X, Siete Partidas, ed. G. López, París, Lecointe et Lasserre, 1843): «Et pelegrino tanto quiere decir como extraño que va a visitar el Sepulcro de Jerusalem et los otros santos lugares en que nuestro señor Jesu Cristo nació, et visquió et prisó muerte en este mundo, ó que anda en pelegrinaje á Santiago ó á otros santurios de luenga tierra et estraña. Et como quier que departimiento es quanto en palabra entre romero et pelegrino; pero segunt comunalmente las gentes lo usan, asi llaman al uno como al otro. Et las maneras destos romeros et pelegrinos son tres: la primera es quando por su propia voluntad et sin premia ninguna va en pelegrinaje á alguno destos santos lugares; la segunda es quando lo face por voto ó por promision que fizo á Dios; la tercera quando alguno es tenudo de lo facer por penitencia quel fuese puesta que ha de complir» (Título XXIV. Lei I).

${ }^{7}$ Elvira Fidalgo, «Peregrinos...», art. cit., p. 207; Daniel Grégorio, «Pèlerinages et chemin initiatique...», art. cit., pp. 134-135.

${ }^{8}$ Joaquín Rubio Tovar, «La peregrinación como encuentro», Liébana y letras: ciclo de conferencias, septiembre 2006-enero 2007, Santander, PUbliCan, Ediciones de la Universidad de Cantabria, 2008, pp. 67-82.

${ }^{9}$ Segundo a MedDB -Mercedes Brea (dir.), Base de datos da Lírica Profana Galego-
} 
con que, malia que nas Siete Partidas sedistingue a figura do romero da do pelegrino, o código lexislativo afonsino recoñece que os dous termos eran empregados indistintamente polas xentes, sen que polo tanto se establecese unha diferenza esencial en canto ao valor espiritual da viaxe ${ }^{10}$.

No interior da colección, chama a atención que o substantivo viage $^{11}$ non apareza máis que nunha ocasión («A moça, que sage / foi, aquel viage / fez com' é usage» CSM195: 151-153) ${ }^{12}$, e non se coñecen derivados ${ }^{13}$. Porén, estreitamente ligados á noción de desprazamento ou tránsito recóllense na obra outras expresións, como caminno, via, carreira e semedeiro: «e a Seixon de caminno | começou toste d' andar» (CSM53: 33), «mas foi errar o camynno, | e anoiteceu-ll' enton / per u ya en un monte, | e viu d'estranna faiçon» (CSM189: 8-9), «O cego creeu a dona, | e tan toste sse partiu / dela e foi sa carreira, | tanto que ss' el espediu» (CSM278: 48-49), «D' ir cada dia por agua $\mid$ mui longe a hũa fonte / que nacia en un vale $\mid$ juso a pe desse monte, / yndo per un semedeiro. [...]» (CSM191: 15-17), «meteu-sse na via / muit' apressurosa- / ment', e non guardou degredo» (CSM195: 186-188)...

En xeral, nas narracións que conforman a obra, a marcha adoita aparellar unha aventura inesperada, pero grazas á intervención mariana conclúe nun final feliz, no que o viaxeiro acaba espiritualmente beneficiado, independemente de se se trataba dun peregrino que se desprazaba por razóns relixiosas ou se se identificaba con outro tipo

Portuguesa (MedDB), versión 2.3.3. Centro Ramón Piñeiro para a Investigación en Humanidades. [En liña] Enlace: <http://www.cirp.es/> [Consulta 4/4/2016]-, na lírica profana galegoportuguesa rexístrase pelegrin nunha cantiga de escarnio de Joan Soarez Coelho (79,26: e ar torná-ss'o mouro pelegrin). Rexístrase tamén palmeyro nunha cantiga de Pedr'Amigo de Sevilha $(116,31)$ dedicada a Pero d'Ambroa, que viaxou a Ultramar. É maior o uso de romeu, que parece rexistrarse unicamente en cantigas de natureza escarniña ou cantigas morais $(2,17 ; 14,12 ; 18,41$; $49,5 ; 64,23 ; 94,13 ; 97,28 ; 116,15)$ e romaria, especialmente frecuente en cantigas de amigo. Sobre as cantigas de romaría pode consultarse Mercedes Brea, «Las "Cantigas de Romería” de los juglares gallegos», Santiago Fortuño Llorens, Tomàs Martínez Romero (eds.), Actes del VII Congrés de l'Associació Hispánica de Literatura Medieval (Castellò de la Plana, 22-26 de setembre de 1997), Castelló de la Plana, Publicacions de la Universitat Jaume I, 1999, pp. 381-396.

${ }^{10}$ Daniel Grégorio, «Pèlerinages et chemin initiatique...», art. cit., p. 131.

${ }^{11}$ Segundo Corominas e Pascual (Diccionario crítico etimológico castellano e hispánico, Madrid, Gredos, 1980-1991, 6 vols, s. v. via), no castelán sería tomado do catalán ou occitano viatge, que partiría do latín VIATǏCUM 'provisións ou diñeiro para a viaxe', pero a súa documentación é tardía, advertindo que falta aínda en Nebrija e nos glosarios de ata 1400.

${ }^{12} \mathrm{Os}$ treitos da obra que se reproducen no presente traballo seguen a edición de Walter Mettmann (Alfonso X, Cantigas de Santa Maria, Madrid, Castalia, vol. 1, 1986, vol. 2, 1988, vol. 3, 1989), servíndonos da numeración asignada por este editor ás cantigas e aos versos.

${ }^{13}$ Tampouco foi de uso estendido na lírica profana, segundo se desprende da pesquisa do termo na MedDB [Consulta: 2/6/2015] e en GLOSSA -Manuel Ferreiro (dir.), Glosario da poesía medieval galego-portuguesa (GLOSSA), Universidade da Coruña. [En liña] Enlace: < http:// glossa.gal> [Consulta: 2/6/2015]-. De procurarmos a expresión en Ernesto González Seoane et alii (dirs.), Dicionario de Dicionarios do Galego Medieval, in Recursos Integrados da Lingua Galega, [En liña] Enlace: <http://sli.uvigo.es/> [Consulta: 4/4/2016], aparece rexistrada por Mettmann no seu glosario das CSM, e por Ramón Lorenzo (Sobre cronologia do vocabulário galego-português, Vigo, Galaxia, 1968, s. v. viage) en textos de cronoloxía posterior. 
social ${ }^{14}$. Desde o mesmo epígrafe da composición, pode anunciarse cal é o tipo de aventura ou perigo que lle tocará encarar ao viaxeiro, advertíndose obstáculos de moi diversa natureza: os encontros e as astucias do demo (como lle aconteceu ao peregrino que se dirixía á casa de Santigo, na célebre CSM26) ${ }^{15}$, o ataque dun animal salvaxe ou perigoso (como a besta pezoñenta con forma de dragón que infectou o rostro do peregrino da CSM189), perderse por un camiño perigoso e descoñecido (tamén disto é exemplo a CSM189), e as incontables veces en que aparecen inesperadamente inimigos ou asaltadores (do que podemos propoñer como exemplo o caso do doncel da CSM146, a quen, indo en romaría, os seus adversarios cortaron as mans e sacaron os ollos), etc.

Nas páxinas que seguen, centrámonos nalgunhas pasaxes que dan conta dun perigo e, dado o volume da obra e das viaxes que se relatan, seleccionando unha serie de narracións que incorporan unha travesía por mar como motivo temático ${ }^{16}$, interesándonos especialmente polas experiencias emocionais (medo, angustia, congoxa...) que se dan nestes episodios.

\section{DO MAR E DOS SEUS TORMENTOS}

O mar era un medio temido e considerado hostil polas xentes viaxeiras do medievo e aparece como motivo recorrente na literatura ${ }^{17}$. Á diferenza do que acontece a miúdo nas cantigas profanas ${ }^{18}$, nas narracións marianas preséntase normalmente como indócil e perigoso:

${ }^{14}$ Como explica D. Grégorio: «D’autre part, les Cantigas évoquent des voyages à but commercial et au cours desquels se manifeste la puissance de la Vierge, en transformant le simple périple en expérience mystique; ces récits pourraient donc élargir la notion de voyage spirituel à tous les déplacements» («Pèlerinages et chemin initiatique...», art. cit., p. 133).

${ }^{15}$ Sobre este milagre, pode verse Daniel Grégorio, «Pèlerinages et chemin initiatique...», art. cit., pp. 136-137.

${ }^{16}$ Os milagres ambientados no mar foron atendidos por Valeria Bertolucci Pizzorusso («Altri mari nelle Cantigas de Santa Maria: testi ed immagini», en Actas do Congreso o Mar das Cantigas, Santiago de Compostela, Xunta de Galicia, 1998, pp. 291-299), nun traballo en que se inclúe un repaso polos distintos perigos do mar, acompañado dunha útil reprodución das escenas representadas en $T$ e $F$.

${ }^{17}$ A este respecto, poden ser ilustrativos: Jean Delumeau, El miedo en Occidente (siglos XIV-XVIII). Una ciudad sitiada, Madrid, Taurus, 2002, pp. 53-69; Pablo Martín Prieto, «Las huellas del miedo en la literatura de viajes medieval: una aproximación metodológica», Espacio, Tiempo y Forma, Serie III. $H^{a}$ Medieval, 25 (2012), pp. 255-284; Vera Moya Sordo, «El miedo en el escenario del viaje atlántico ibérico. Siglos XV-XVI», Cuadernos de Estudios Gallegos, LX, 126 (2013), pp. 225-253; Christiane Villain-Gandossi, «En la Edad Media, el dominio del miedo», en A. Corbin e H. Richard (dirs.), El mar. Terror y facinación, Barcelona, Paidós, 2005, pp. 76-80; Chantal Connochie-Bourgne (dir.), Mondes marins du Moyen Âge, Aix-en-Provence, Presses universitaires de Provence, 2006. [En liña] Enlace: <http://books.openedition.org/ pup/3814> [Consulta: 9/5/2016].

${ }^{18}$ A propósito da dimensión simbólica do mar na poética amorosa pode verse, sobre todo para as cantigas de amigo, Maria do Rosário Ferreira, Águas doces, águas salgadas. Da funcionalidade dos motivos aquáticos na Cantiga de Amigo, Porto, Granito Editores, 1999, pp. 41-81; tamén Valeria Bertolucci Pizzorusso, «Altri mari...», art. cit., pp. 292. Aínda sobre o uso do mar como motivo na produción profana, pode consultarse Mercedes Brea, «Pai Gómez Chariño y 
Nel racconto miracolistico il mare è crudamente presente nella sua elementare e potente natura, che quasi mai è benigna; qui si trovano le coitas do mar in senso letterale e concreto, tempeste e naufragi, dai quali solo per intervento della Vergine è concesso ad alcuni devoti di scampare ${ }^{19}$.

Unha das razóns polas que decidimos centrarnos en cantigas que incorporan o motivo temático dunha viaxe por mar baséase na frecuencia con que o tema aparece explicitamente asociado á noción do perigo. Así, o substantivo perigoo e o verbo correspondente, perigoar, rexístranse no interior de 17 cantigas, das cales 8 incorporan unha viaxe por mar. Con frecuencia, a expresión pode testemuñarse xa no epígrafe da composición e, nunha das cantigas, o adxectivo perigoado repítese no refrán.

CSM36: Esta é de como Santa Maria pareceu no maste da nave, de noite, que ya a Bretanna, e a guardou que non perigoasse.

CSM172: Como Santa Maria de Salas livrou un mercador do perigoo do mar.

CSM236: Como hũa moller perigoou no mar, e tragia un fillo pequeno nos braços; e feze-a Santa Maria per cima das aguas andar de pe, assi como yria per un mui bon chão.

CSM267: Como Santa Maria livrou un mercador do perigoo das ondas do mar en que cuidava [morrer] u caera dũa nave.

CSM313: Esta é da nave que andava en perigoo do mar, e os que andavan en ela chamaron Santa Maria de Vila-Sirga, e quedou logo a tormenta.

CSM339: Esta é como Santa Maria guardou ũa nave que non perigoasse no mar.

CSM371: [C]omo Santa Maria do Porto guariu ũa moller que perigoara dũa pinaça e caera no mar.

A [de] que Deus pres carn'e foi dela nado,

ben pode valer a todo perigoado. (CSM267: refrán)

\subsection{Tormentas}

$\mathrm{Na}$ colección, un dos riscos máis recorrentes -e, probablemente, un dos maiores temores de todo viaxeiro medieval por mar-consistía en que se levantase unha gran tormenta que perturbase a estabilidade do barco e a seguridade dos pasaxeiros que ían a bordo. Como

el mar», en C. Alvar e J. M. Lucía Megías (eds.), La literatura en la época de Sancho IV (Actas del Congreso Internacional, Alcalá de Henares, 21-24 de febrero de 1994), Alcalá de Henares, Universidad de Alcalá de Henares, 1996, pp. 141-152, e «Coita do mar, coita de amor», en M. Brea (coord.), Estudos sobre léxico dos trobadores, Santiago de Compostela, Universidade de Santiago de Compostela (Verba, anuario galego de filoloxía. Anexo 63), 2008, pp. 215-229; así como varios dos traballos recollidos no volume colectivo Actas do Congreso o Mar das Cantigas, op. cit.

${ }^{19}$ Valeria Bertolucci Pizzorusso, «Altri mari...», art. cit., p. 292. 
motivo temático non é exclusivo das Cantigas de Santa Maria, senón que adoito se incorpora en textos doutra natureza, sendo un dos grandes obstáculos relatado nos libros de viaxes medievais e figurando tamén entre os motivos frecuentes incorporados nas representacións iconográficas deste período ${ }^{20}$. Segundo explica Martín Prieto:

uno de los motivos que con mayor frecuencia aparece asociado a vivencias angustiosas y experiencias-límite en el contexto de las relaciones de viajes en tiempos medievales concierne a los peligros del medio y del entorno: los embates de un clima extremado y de fenómenos atmosféricos como las tormentas, que, especialmente en el mar, constituyen uno de los motivos de miedo más indeleblemente asociado, en la mentalidad y el recuerdo de aquellos hombres, a la experiencia de sus viajes.

Centrándonos en estas últimas, hemos de reconocer la extraordinaria frecuencia con que las travesías por mar (y dentro de éstas, las tormentas) aparecen caracterizadas como motivos de temor en las relaciones de viajes. Para empezar, la sola vista del mar, siempre impresionante, podía llegar a atemorizar a quienes nunca se habían aproximado a la costa ${ }^{21}$.

$\mathrm{Na}$ colección mariana, en ocasións, utilizáronse expresións para referirse ás distintas emocións experimentadas polos que se senten intimidados ante a ameaza dun fenómeno natural no medio do mar. Este é o caso da CSM33, onde se narra como unha embarcación con máis de oitocentos romeiros viaxa con destino a Acre, pero, durante o traxecto, levántase unha tormenta que afecta á armazón da nave e comeza a afundirse. As xentes tratan de fuxir nun pequeno batel, mais un dos romeiros salta fallidamente e cae na auga; os demais, precavidos dos perigos do mar polas historias oídas, e véndose desvalidos, foxen o máis rápido posible. Ademais, dise que, con angustia (coita) por chegar a salvo ao porto, pisaron terra con pavor e medorentos:
Os do batel a remar
se fillaron sen tardar
per sse da nav' alongar
e fugir dos escarmentos,
de que oyran falar,
dos que queren perfiar

\footnotetext{
${ }^{20}$ Precisamente sobre isto último afirmaba C. Villain-Gandossi: «A partir del simple examen de un corpus substancial de las imágenes del navío medieval, constituido a partir de representaciones sobre todo tipo de soportes, parece que muy pocos clichés, cargados de una realidad vívidamente experimentada, tuvieron más éxito en la época medieval que el de la «nave en la tempestad». Ningún episodio se repite más regularmente en la vida de numerosos santos que el de una travesía, real o simbólica, representada en las miniaturas, las vidrieras o los bajorrelieves de las iglesias» («En la Edad Media...», art. cit., p. 71).

${ }^{21}$ Pablo Martín Prieto, «Las huellas del miedo...», art. cit., p. 268.
} 
sen aver acorrimentos.

Gran poder á de mandar...

E con coyta d' arribar, ssa vea foron alçar, e terra foron fillar con pavor e medorentos; e enton viron estar aquel que perigoar viran enos mudamentos. Gran poder á de mandar... (CSM33: 39-54).

Neste tipo de situacións, non é descoñecida a participación de expresións que tratan de plasmar certa congoxa ou ansiedade, experimentada pola posibilidade dunha irreversible desgraza ante o perigo. Este parece ser o valor que adquire a forma coita en certos contextos - como o correspondente ao fragmento da CSM33 que acabamos de reproducir-. Hai que ter en consideración que, tanto na lírica profana como na relixiosa, non se testemuña angustia, do substantivo latino ANGUSTIA, o que non debería identificarse coa «inexistencia» da emoción $^{22}$, que talvez, nos textos líricos galego-portugueses, se plasmou de maneira preferente mediante outras expresións. A palabra coita é ben coñecida na produción lírica tanto profana como relixiosa, pero, máis normalmente, é identificada como referente da dor e da aflición (a miúdo, nas cantigas de amor e de amigo, os termos afan, pena, dano e mal funcionan como sinónimos de coita ${ }^{23}$. Non obstante, neste tipo

\footnotetext{
${ }^{22}$ Segundo Corominas e Pascual (DCECH, s. v. angustia), en castelán presentaríase na primeira metade do século XV, en Santillana. En relación ao termo latino, rexístrase angostura na CSM321:68, pero non figura en relación a unha emoción, senón como 'estreiteza'. A expresión angustura recóllese tamén na versión galega da General Estoria, aparecendo proximamente á coita: «Aly foy Jupiter em grande coyta et angustura: da hũa parte por que era cousa moy descomunal et máá de fazer de negar seus amores da cousa que moyto amaua; da outra parte por que averia sospeyta em nõ lla dar; et avergonça que el avia da rreyna mãdaua lla dar, ho amor que avia de Yo defendia quea nõ desse; et ho amor vençera aavergonça senõ por que hũa vaca que era tam pequena dadiua, [se] nõ fosse dada arreyna, sua yrmãa et moller, nõ paresçeria que era vaca mays outra cousa tam grande que non poderia [séér] osmada nẽ posta em preço, et ouvo lla adar», Ramón Martínez López (ed.), General Estoria. Versión gallega del siglo XIV. Ms. O. I. 1. del Escorial, Oviedo, Publicacións de Archivum, 1963, p. 251, en Corpus Xelmírez [En liña] Enlace: $<$ http://sli.uvigo.es/xelmirez/> [Consulta: 10/5/2016]. [Incorpora as correccións de Ramón Lorenzo e Xosé Luís Couceiro, «Correccións á edición da General Estoria de Ramón Martínez López (I)», en Cinguidos por unha arela común. Homenaxe ó profesor Xesús Alonso Montero, Santiago de Compostela, Universidade de Santiago de Compostela, 1999, 2 vols., vol. 1, pp. 595-627; «Correccións á edición da General Estoria de Ramón Martínez López (II)», en Homenaxe ó profesor Camilo Flores, Santiago de Compostela, Universidade de Santiago de Compostela, 1999, 2 vols., vol. 2, pp. 209-233].

${ }^{23}$ A etimoloxía e os usos de coita na lírica profana occitana e galego-portuguesa foi obxecto de estudo na tese de doutoramento, aínda inédita, de Antonio Augusto Domínguez Carregal, $O$ léxico da coita amorosa na lírica galego-portuguesa, Santiago de Compostela, Universidade de Santiago de Compostela. Departamento de Filoloxía Galega. Programa de doutoramento en Lingüística (presentada en 2015).
} 
de episodios en que se narra un accidente mariño no interior das cantigas marianas, o termo parece remitir de forma bastante clara a unha vivencia emocional doutra índole, máis ben achegada á angustia e á ansiedade por saír dunha situación de apuro para librarse do perigo. Esta perspectiva que ofrecen as Cantigas de Santa Maria da coita do mar lévanos a lembrar a célebre canción Quantos og'andam eno mar $a q u i^{24}$, do trobador galego Pai Gomez Charinho, na cal o substantivo coita está posto en relación ao mar, ao amor e á morte, e parece aceptable interpretar o termo con este mesmo sentido (a angustia do mar / a angustia do amor) ${ }^{25}$.

Máis exemplos do uso de coita con este valor no interior da colección mariana encóntranse na CSM313 («Esta é da nave que andava en perigoo do mar, e os que andavan en ela chamaron Santa Maria de Vila-Sirga, e quedou logo a tormenta»), na que, novamente, se introduce o motivo da tormenta que ameaza a todos os da nave de morrer no medio do mar ao terse producido unha rotura da embarcación. Neste caso, nin sequera chega a especificarse a causa que reúne aos que van na travesía:

Hũa nave periguada $\mid$ andava, com' aprendi, pelo mar en gran tormenta, | e quanta gent' era y estavan en mui gran coita; | e, assi com' eu oý, a nav' era ja quebrada. | Des i o mar a crecer Ali u todo-los santos $\mid$ non an poder de põer..

Começou tan feramente | e engrossar cada vez, e volvendo-s' as arẽas; | des i a noite sse fez, cona tormenta mui forte, | negra ben come o pez, demais viian da nave $\mid$ muitos a ollo morrer. Ali u todo-los santos $\mid$ non an poder de põer..

E porende braadavan | e chamavan «Sennor Deus», e «San Pedr'» e «Santiago», | «San Nicolas», «San Mateus», e santos muitos e santas, | outorgando que romeus

\footnotetext{
${ }^{24}$ Corresponde á cantiga 114,17 na $M e d D B$.

${ }^{25}$ A propósito da asociación entre coita e mar na lírica profana, véxanse os traballos da prof. Mercedes Brea, «Pai Gómez Chariño...», art. cit.; «¿Mariñas ou barcarolas?», O Mar das Cantigas, op. cit., pp. 301-316; «Coita do mar...», art. cit. Neste sentido, é especialmente significativa na produción poética de Pai Gomez Charinho, trobador que, como dixemos, falou nunha mesma cantiga da coita d'amor e da coita do mar; sobre esta, explicaba M. Brea: «(114,17) é un caso único de explicación do que supón a coita de amor, unha paronomasia clásica na que interveñen mar - amar / amor - morte, para indicar que as penas producidas polo amor (e a mesma morte por amor) superan ós propios perigos que entraña o mar, como podemos comprobar lembrando os versos de refrán e máila fiinda:

coita d'amor me faz escaecer

a muy gran coita do mar, e têer por mayor coita a que faz perder coita do mar, que muitos faz morrer». Mercedes Brea, «¿Mariñas...», art. cit., p. 303.
} 
de grado seus seerian | se lles quisesse valer. Ali u todo-los santos | non an poder de põer..

Todos en perigoo eran | e en gran coita mortal, e ben cuidavan que fossen $\mid$ mortos, non ouves[s]' y al; mais ũu crerigo que era $\mid y$, pois viu a coita tal e oyra dos miragres $\mid$ da Santa Virgen dizer Ali u todo-los santos | non an poder de põer... (CSM313: 21-40).

Nesta parte da cantiga, pode apreciarse a repetición do termo coita, mesmo enfatizado cos modificadores en mui gran coita, en gran coita mortal e a coita tal, que neste contexto participarían na explícita manifestación da congoxa e ansiedade derivadas, primeiro, de que a nave quebrase e, segundo, e como consecuencia do anterior, das altas probabilidades de afogaren todos no medio do mar, mentres vían como ían caendo e finando outros. Ademais, na descrición da situación de perigo, reitérase esta noción mediante a repetición por derivatio (nave periguada andava e todos en perigoo eran), recóllese e incídese na idea de morte, non só explícita nos versos «demais viian da nave | muitos a ollo morrer» (v. 29), «Todos en perigoo eran | e en gran coita mortal / e ben cuidavan que fossen | mortos, non ouves[s]' y al» (vv. 36-37), senón tamén a través da descrición da tormenta, coa introdución do concepto noite e do símil negra ben come o pez, que colaborarían na intensificación do pesimismo e na noción da morte ${ }^{26}$, deseñando unha dramática situación entre os que, véndose desvalidos, se encomendaban e pregaban afervoadamente a todos os santos e santas. Con todo, cando por intervención de María se realiza o milagre, a paz e a seguridade veñen opoñerse á axitación e escuridade anterior; o novo estado é anunciado pola chegada á nave dunha pomba branca e inclúense no discurso termos que remiten á luz e á claridade, que, neste contexto, poden entenderse vinculados á divindade, á harmonía e á felicidade que proporciona o milagre ${ }^{27}$.

${ }^{26}$ Esta adxectivación é usual en descricións do mar nas obras do período medieval, especialmente cando o perigo no medio mariño deriva dunha tormenta. Sobre esta cuestión, pode consultarse Danièle James-Raoul, «L'écriture de la tempête en mer dans la littérature de fiction, de pèlerinage et de voyage», Chantal Connochie-Bourgne, Mondes marins ..., op. cit., pp. 217229 [Consulta: 9/5/2016]. Igualmente Villain-Gandossi («En la Edad Media...», art. cit., p. 74) recolle algúns exemplos reproducidos en romans onde que se presenta o mar negro, horrible, escuro, tenebroso...

${ }^{27}$ Contraste que poderemos ver baixo a luz das explicacións de D. James-Raoul («L'écriture de la tempête...», op. cit., s.p., parágrafo 11): «Dans les récits de croisades ou de pèlerinages, la tempête n'est pas, sauf exception, un objet de poésie ou une machine littéraire: elle apparaît comme l'une des nombreuses aventures possibles qui rendent si dangereux le voyage et montrent à quel point le salut ne dépend que de ce Dieu dont le pèlerin ou le croisé veulent justement se rapprocher. Sa représentation s'échappe ainsi du moule conventionnel relevé précédemment: la mise en scène gagne quelque souplesse, certains détails apportent la vérité des faits, par-delà les hyperboles qui perdurent, nécessaires pour faire sentir l'horreur indicible, le vocabulaire est moins restreint, plus souvent technique. Les tempêtes nocturnes sont parmi les plus saisissantes parce que leur sauvagerie traduit explicitement une symbolique diabolique, précisément 
Unha narración con numerosas concomitancias a esta última que acabamos de referir é a da CSM36, ambientada no mar da Bretanna; non se especifica cal é o obxectivo inicialmente perseguido coa viaxe, aínda que se di que se trata dunha gran companna d'omees que ían por sa prol buscar, no que todos punnades ${ }^{28}$, polo que podería tratarse de comerciantes, pois a economía foi un factor decisivo para que as xentes ousasen sucar os mares medievais e a colección mariana dá bo testemuño deste feito.

Malia ser un texto máis conciso ca o anterior, repítense os tópicos da tormenta mariña, a ambientación na escuridade da noite, o medo a morrer e a impresión de total desamparo en que se sumen os navegantes, servíndose aquí de dous signos asociados á experiencia emocional: o gemer e o chorar.

E u singravan pelo mar, atal foi ssa ventura que sse levou mui gran tormenta, e a noit' escura se fez, que ren non lles valia siso nen cordura, e todos cuidaron morrer, de certo o sabiades. Muit' amar devemos en nossas voontades...

Pois viron o perigo tal, gemendo e chorando os santos todos a rogar se fillaron, chamando por seus nombres cada un deles, muito lles rogando que os vẽessen acorrer polas ssas piedades.

Muit' amar devemos en nossas voontades... (CSM36: 10-19).

Nesta CSM36 prodúcese finalmente o milagre mediante a intervención de María e, outra vez, como no milagre anterior, a pacificación das augas se acompaña dun resplandor procedente da divindade -en intencionado contraste coa escuridade que provocara a tormenta nocturna-, o que colabora na plasmación dun regreso a un estado de seguridade, paz e total sosego:

E dizian: «Sennor, val-nos, ca a nave sse sume!»

E dizend' esto, cataron, com' er é de costume, contra o masto, e viron en cima mui gran lume, que alumẽava mui mais que outras craridades. Muit' amar devemos en nossas voontades...

infernale, composée de violence, de ténèbres, de fracas assourdissant, de terreur et d'une intense confusion de tous les éléments».

${ }^{28}$ Non é a única ocasión en que se utiliza esta sorte de expresión como causa que empurra ás xentes a desprazarse por mar; na CSM339, dise que no reino de Murça hai un lugar chamado Alecante onde van moitos por mar «e per terra, ca en logar está / d'as gentes muit' y de sa prol fazer» (CSM339: 17-18). 
E pois lles est' apareceu, foi o vento quedado, e o ceo viron craro e o mar amanssado, e ao porto chegaron cedo, que desejado avian; e se lles proug' en, sol dulta non prendades. Muit' amar devemos en nossas voontades... (CSM36: 30-39).

Continuando coa presenza destes tópicos noutras cantigas, a CSM267 está dedicada a un mercador, morador na zona de Portugal entre Douro e Miño, que prometeu ir a Rocamador en romaría en canto lle fose posible. Con motivo da súa actividade mercantil fretou a súa nave para ir dirección a Flandes, pero na viaxe sufriu o azoute dunha irada tormenta que fixo que a xente temese pola súa vida e salvación (xa que morrer no mar supuña, normalmente, non recibir os últimos sacramentos):

Levantou sas ondas fortes feramente sobr' aquela nave, que aquela gente cuidou y morrer, que logo mantenente chorou e coidou enton y seu pecado (CSM267: 40-43).

Unha onda tirou co home no mar e, estando nesta crítica situación, lembrouse de pedir auxilio a Santa María; de tal maneira, nesta parte do discurso o termo torment ${ }^{29}$ pode interpretarse tamén como 'aflición' ou mesmo como 'situación turbulenta ${ }^{30}$. Repárese ademais que, nos seguintes versos, se alude á acción do demo no potencial afogamento do home:

mai-lo demo, que senpre nosco traballa, quisera que morress' y log' affogado. $A[d e]$ que Deus pres carn'e foi dela nado...

El andand'assi en aquela tormenta, nenbrou-sse da Vigen que senpr' acrecenta eno nosso ben; [...] (CSM267: 52-57).

${ }^{29} \mathrm{~A}$ partir do latino en plural neutro TORMĚNTA, 'tormentos'; segundo Corominas e Pascual (DCECH, s. v. torcer), rexístrase tormenta desde mediados do século XIII co significado xeral e etimolóxico 'desgraza', 'infelicidade'.

${ }^{30}$ Valor que tamén se lle daría na lírica profana, nunha cantiga escarniña de Joan Soarez Somesso, repetido no v. 3 de cada estrofa. Véxase M. Brea, «Coita do mar...», art. cit., p. 226 (nota 27). Por outra banda, na lírica profana recóllese o sintagma en rima tormenta do mar en dúas cantigas de escarnio que presentan tamén como característica común o estaren dedicadas a Pero d'Ambroa: a composición Pero d'Anbroa, senpr'oy cantar de Gonçal'Eanes do Vinhal (MedDB 60,11; data de consulta 4-4-2016) interesa especialmente en relación ao tema estudado por desenvolver o tema do medo no medio mariño, xa que ao escarnecido Pero d'Ambroa se lle recrimina non aver medo das inclemencias do tempo atmosférico no mar, nin da posibilidade de rotura e afundimento da nave. O outro texto é Quen mh'ora quysesse cruzar e é da autoría de Pedr'Amigo de Sevilha (MedDB 116,31), como o anterior, dedicado á peregrinación de Pero d'Ambroa ata Xerusalén. 
A modo de discurso directo, reprodúcese o afervoado rogo que o mercador dirixiu á Madre de Deus e Sennor. Na súplica, que abrangue os versos 60-74, poderíase subliñar a participación de expresións de emocións diversas, como a angustia e a aflición, a través do uso dos termos coita e coitado, pesares e atormentado; e a procura de amparo mediante a incorporación das expresións por mercee, non me desanparar e escudo. Coa intervención da Virxe, calma a marea e o home arriba san e salvo a terra «que sol non sentiu coita nen rancura» (v. 86), isto é, nin angustia nin tristeza ${ }^{31}$.

Tamén por razóns económicas viaxarían aqueles da CSM112, onde se narra como unha nave cargada de trigo e cebada sufriu o azoute dunha tormenta, que esnaquizou o navío e puxo en risco os bens que eran transportados. Deixan a nave sen grado, soben a un pequeno batel a gran pẽa ${ }^{32}$, e rezan á Virxe para que garde a mercadoría e os libre do perigo. Cando chegan ao porto ven varada a nave e a carga, que xa estimaran perdida, mantida seca e a salvo.

Como se desprende dalgunha das cantigas ata agora vistas, e pode terse como un motivo que aparece de modo habitual nos milagres, a solución para evitar o perigo inminente consiste en rogar coa máxima devoción. Este socorrido remedio podería xulgarse xustificado pola temática relixiosa e devocional da obra; non obstante, o rezo aos santos máis diversos foi unha das reaccións habituais que se rexistran nas narracións incluídas nos libros de viaxes, pois a través da oración e da súplica, o viaxeiro intimidado por un mal pretendería minimizar e dar alivio ao medo experimentado ${ }^{33}$. No caso desta colección, evidentemente, non serve de nada dirixirse a un santo calquera: só unha piadosa súplica a María pode calmar ao perigoado -como se designa nas Cantigas a aquel que está en risco-e restablecer o equilibrio perdido, auxiliando aos que sofren as coitas do mar. Así se promociona na CSM339, onde, ademais, o substantivo tormenta tamén pode entenderse como sinónimo dos termos coita, pesar e door:

${ }^{31}$ No interior das Cantigas de Santa Maria, o termo rancura recóllese sete veces, sempre en posición de rima; en seis ocasións é expresión do disgusto ou tristeza, como acontece neste contexto, e só nunha ocorrencia parece asociarse preferentemente á expresión da ira.

${ }^{32}$ Esta forma patrimonial (a partir do latín POENA), aparece xunto a pena nos textos das Cantigas de Santa Maria e da lírica profana; sobre a presenza destas dúas variantes na produción dos trobadores, explicaba Mercedes Brea: «La forma patrimonial pẽa (< POENA) sólo se registra en dos cantigas de escarnio, aunque es difícil decidir si la alternancia entre pẽa y pena (o entre pẽado y penado) en los cancioneros es real o responde a problemas de transcripción y edición, pues la $<$ n $>$ suele abreviarse y los copistas (igual que los editores) podrían, en algún caso, haberla reinterpretado erróneamente (en los dos sentidos: abreviatura por $<$ n $>0<$ n por abreviatura). Como sustantivo, en las cantigas de amor y de amigo, sólo aparece en plural y su escasa frecuencia podría explicarse, al menos en parte, porque presenta un claro -y doble-problema de homonimia, ya que pena es también el resultado gallego de PENNA 'pluma' y PINNA 'roca, peña'» («La expresión de las emociones en la lírica gallego-portuguesa (primera aproximación)», en A. Decaria e L. Leonardi, «Ragionar d'amore». Il lessico delle emozioni nella lirica medievale, Firenze, Edizioni del Galluzzo per la Fondazione Ezio Franceschini, 2015, pp. 106-107).

${ }^{33}$ Pablo Martín Prieto, «Las huellas del miedo...», art. cit., pp. 277-279. 
En quantas guisas os seus acorrer

sab' a Virgen, non se pode dizer.

Ca acorre en coit' e en pesar

e en door a quena vai chamar,

e acorre nas tormentas do mar; (CSM339: 3-7).

Este xogo baseado nos dous valores que pode presentar o substantivo tormenta neste tipo de contexto mariño non aparece de maneira exclusiva nesta CSM339 e na xa referida CSM267 (v. 55); no refrán da CSM172 ${ }^{34}$ pode entenderse tormentas como 'fenómeno atmosférico' ou como 'tormento', 'aflición', remitindo polo tanto a unha emoción:

A Madre de Jesu-Cristo | que ceos, terras e mares

fez, poder ád'as tormentas | toller en todos logares (CSM172: refrán).

E aínda máis claramente se reproduce no refrán da tamén xa comentada CSM36, onde, no entanto, o substantivo utilizado é tempestades.

Muit'amar devemos en nossas voontades

a Sennor, que coitas nos toll'e tempestades.

\subsection{Corsarios}

Aínda que debeu ser un dos obstáculos máis temidos no mar, a tormenta non era a única ameaza á que se expuña o home viator da Idade Media. Así, na CSM35, viaxeiros con distintas profesións e motivacións xúntanse nunha travesía mariña; preséntasenos como un deán, chamado Maestro Bernaldo, primeiro percorre Francia transportando unhas valiosas reliquias da Virxe (tratábase do seu leite e dos seus cabelos, estes envoltos nun cendal, metidos nunha arca de ouro, pois a igrexa onde estes restos sagrados estiveran depositados fora consumida polo lume e, con intención de reconstruíla, os cregos decidiron promocionar as reliquias, sendo transportadas polo referido maestre) e, máis tarde, viaxa ata Inglaterra; decide entón, para manter a salvo os milagreiros restos, viaxar con eles ata a Bretaña na nave dun mercader chamado Colistanus, onde ían moitos outros ricos comerciantes. A bonanza e a pracenteira travesía mudan drasticamente cando se senten invadidos por unha flota de seis galeas de

${ }^{34}$ A CSM172, que leva por título «Como Santa Maria de Salas livrou un mercador do perigoo do mar», está dedicada a un comerciante que se dirixía a Acre coa súa nave chea de mercadorías, mais durante o traxecto unha tormenta fai caer o mastro e a vela. A promesa de tornar romeiro e viaxar a Santa María de Salas serve para calmar a tormenta e ter bo vento para chegar a terra, perdendo o medo e os maos pensamentos de morte que o invadían anteriormente. Despois de vender a mercancía, diríxese como romeiro a Salas con loores e cantares e ofrece unha cruz de cristal en ofrenda porque arribara ao porto san e salvo. 
corsarios. O medo recoñécese explicitamente no texto mediante o sintagma ar ouveron gran pavor, en directa oposición ao mui gran sabor co que se relaciona por efecto da rima.

E u ja pelo mar yan | todos a mui gran sabor, ouveron tan gran bonaça $\mid$ que non podia mayor; e estando en aquesto, $\mid$ ar ouveron gran pavor, ca viron ben seis galeas | leixar-ss' a eles correr, $[\ldots]$

De cossarios que fazian | en aquel mar mal assaz. (CSM35: 45-48, 50).

Porén, ese medo trocará en valor grazas á compañía das reliquias marianas, con recoñecidos poderes taumatúrxicos, de tal modo que cando os temidos piratas - principal ameaza dos viaxeiros-devotos nesta narración- tratan de cargar contra os relixiosos e os comerciantes, ten lugar o milagre: levántase un bravo vendaval que resulta devastador e afasta os atacantes (polo que neste texto o estado tormentoso no medio mariño é azoute para aqueles que representan o auténtico perigo para os navegantes) ${ }^{35}$. Pero a narración non finaliza aí. Os mercaderes, que procedían de Flandes e de París, indebidamente recolleron aquilo que tiñan ofrecido a María e, unha vez chegados á terra, procuraron intercambiar os bens por la, provocando, desta vez, a intervención de Deus:

querendo vingar sa Madre, | fez com' aquel que aduz gran poder de meter medo | que ll' ajan de correger $[\ldots]$

O gran torto que fezeran | a ssa Madr' Emperadriz, (CSM35: 117-120).

As malas accións dos corsarios e o castigo que recae sobre eles en forma de tormenta non só se testemuñan nesta composición. $\mathrm{Na}$ CSM379, fálase dos ataques e atracos que padecían os novos moradores de Santa María do Porto ${ }^{36}$, onde o Rei pretendía establecer unha gran vila, cara a onde viaxasen e se asentasen mui ricos mercadores, outorgando cartas de repoboación mediante as que se sentisen

\footnotetext{
${ }^{35}$ Precisamente, nesta pasaxe, localízase a descrición dun violentísimo accidente que sofren os atacantes por efecto do estado tormentoso do mar (vv. 82-88).

${ }^{36}$ Obsérvase unha diferenza entre a tormenta como fenómeno natural que ameaza a estabilidade da travesía mariña e fronte á cal os devotos precisan a intervención de María, e a forza da natureza (vendavais ou tormentas) que, controlada pola Nai de Deus, serve para aplacar outro tipo de perigo, como o que ocasionalmente representan os corsarios. De acordo coas observacións realizada por un dos avaliadores do presente traballo, na CSM276 que se contextualiza en Santa María do Porto, esta intervención podería apreciarse en clave política, en vista dos proxectos e aspiracións de Alfonso X respecto a esta cidade e a súa repoboación. Sobre esta última cuestión e tamén sobre as Cantigas de Santa Maria ambientadas neste espazo, pode consultarse o capítulo de Vicenç Beltran, «El Rey-poeta: las Cantigas de Santa María del Puerto», en La corte de Babel. Lenguas poéticas y política en la España del siglo XIII, Madrid, Gredos, 2005, pp. 233-246.
} 
salvos e seguros e que non ouvessen medo de perder os seus haberes nas novas terras. Porén, segundo a cantiga, os corsarios que sucaban o Mediterráneo a miúdo levaban a cabo ataques nos portos:

E por aquesto sas cartas | lles mandava que vẽessen ali salvos e seguros $\mid$ con quanto trager quisessen, e que non ouvessen medo, | enquant' ali estevessen, de perderen do seu nada $\mid$ nen prenderen dessabores A que deffende do demo | as almas dos pecadores...

Per omẽes de sa terra. | Sobr' esto de muitas partes viinnam pera pobrarem, | des Jenua te en Charthes, mais lenno[s] de Catalães, | cossarios chẽos d'artes, faziam danos nos portos, | ca desto son sabedores.

A que deffende do demo $\mid$ as almas dos pecadores... (CSM379: 15-24).

Tamén aquí, como na narración da CSM35, a mala acción dos asaltantes provoca a intervención de María, que, señora daqueles mares, fixo que as inclemencias meteorolóxicas fosen padecidas por aqueles que representaban un perigo que perturbaba a paz dos poboadores. Neste caso, unha forte tormenta impediu a fuxida dos corsarios, que non tiveron máis opción que acollerse en Sevilla e devolver aquilo que indebidamente tomaran:

Assi que pela tormenta, | que foi grand' a maravilla, non souberon que fezessen, | senon ir pera Sevilla a tornar o que fillaran | a pesar da Madr' e Filla de Deus, a que dessonraran. | E daquesto fiadores (CSM379: 40-43).

\subsection{Accidentes e outros azares}

Polo que se ve nas Cantigas de Santa Maria, nas viaxes por mar, o home debeu temer sobre todo as tormentas e os ataques dos corsarios, aínda que habería outros moitos accidentes e azares a afrontar. Así, na CSM371, que aparece ambientada en Santa María do Porto -onde ían novos poboadores e xentes en romaría atraídos polos beneficios outorgados pola Nai de Deus-, cóntase como unha embarcación, excesivamente cargada de homes, mulleres e mercancía, encallou e quebrou contra unhas penas, causando a morte de todos os navegantes excepto a unha muller que se encomendou á Virxe (non obstante, na narración do episodio non se reproducen termos relativos á experiencia emocional). Na CSM236, ambientada no espazo do Mediterráneo, concretamente na zona de Marsella, se define un contexto semellante: navegando, unha galera cargada de xentes despézase contra un penedo; todos morren no naufraxio a excepción dunha muller que viaxaba co seu fillo no colo e é por el por quen implora auxilio de María, ementando a súa condición de nai que sempre velou polo seu fillo: 
E tragendo enos braços | enton aquel fillo seu, eno coraçon a Virgen | rogou, com' aprendi eu, dizendo: «Sennor mui santa, | por amor do Fillo teu que sempre muito guardasti, | queiras este meu guardar.»

(CSM236: 21-24).

No momento da marabilla reprodúcense varias expresións que remiten a emocións comúns neste tipo de contextos: non ajas medo (no v. 30), a levou ben sen afan (no v. 31), porque senpr' aos coitados | enas grandes cuitas val (no v. 38).

$\mathrm{Na}$ CSM339, xa anteriormente citada, comézase afirmando a capacidade de Maria para acorrer na coita, no pesar, na dor e nas tormentas do mar. A pesar desta introdución, a narración non obriga a pensar que o obstáculo que deben sobrepasar os navegantes sexa unha tormenta mariña (tendo en consideración, ademais, a xa referida posibilidade); nesta cantiga, o problema radica na apertura do fondo da nave e o seu asulagamento. Os navegantes rezan aos santos ata que un dos viaxeiros aconsella dirixir un afervoado rogo a María para que os socorra, e a que val aos coitados fai que tres peixes taponen a fenda pola que entraba a auga.

Máis complexa é a aflición que afecta á muller preñada da CSM86, que ía de peregrina ao célebre santuario de Saint Michel. Na parte inicial do cantar, recóllese unha descrición do lugar:

Eno mar que cerca o mund' arredor, na terra que chaman Bretanna Mayor, fez a Santa Madre de Nostro Sennor un gran miragre que vos quero contar. (CSM86: 10-13).

O logar era de mui gran devoçon, mas non podia om' alá ir, se non menguass' ant' o mar, ca en outra sazon non podia ren en sayr nen entrar. (CSM86: 25-28).

A muller é cercada polas ondas dunha marea crecente ${ }^{37}$, configurándose unha situación dramática para quen quixera -pero humanamente non podería- facer fronte á forza da natureza ${ }^{38}$. A mesquinna

\footnotetext{
${ }^{37}$ Situación que fai lembrar aquela en que se encontraba a amiga da célebre cantiga de Meendinho, aspecto xa estudado por Román Raña, «"Illa das illas" (A cantiga de Meendinho e a 86 das Cantigas de Santa María)», Boletín Galego de Literatura, 15-16 (1996), pp. 145-152.

${ }^{38}$ Aínda que, para J. Raimond («Les femmes en chemin...», art. cit., p. 73): «On remarque aussi sur les vignettes de la planche 96 (cantiga 86) que, les pieds au sec, le groupe qui a pu progresser vers le Mont-Saint-Michel plus rapidement que la femme enceinte surprise par la marée, la regarde se noyer. L'accent est mis sans sensationnalisme sur l'impuissance humaine face à la force de la nature et à la puissance mariale. L'image, en général, fait plus cas de l'environnement que le texte».
} 
en coita comezou a chamar pola Virxe ${ }^{39}$, véndose morrer ante a chegada das augas e, simultaneamente, chegándolle o tempo de dar a luz:

A pobre moller, macar quis, non fogiu, ca o mar de todas partes a cobriu; e pois s' a mesquinna en tal coita viu, começou Santa Maria de chamar. Acorrer-nos pode e de mal guardar...

A moller sen falla coidou a fïir quando viu o mar que a vẽo cobrir; e demais chegou-1l' o tenpo de parir, e por tod' esto non cuidou escapar. Acorrer-nos pode e de mal guardar.. (CSM86: 35-44).

O seu rezo á Virxe ten resposta, pois permite que alumbre mentres as ondas fican paradas. A continuación, a muller pode chegar ao santuario de Saint Michel e dar conta do milagre.

Aínda máis diversos serían os perigos que aflixirían a quen debía marchar a lugares moi distantes, nunha viaxe que implicase un traxecto por mar e terra. Un exemplo disto último ofrécese na CSM9, pois trata dun monxe que, tendo por intención facer peregrinación a Xerusalén, recibe o encargo dunha boa dona de traer unha imaxe da Virxe desde Terra Santa. O camiño de ida parece realizarse sen graves complicacións, mais, unha vez que se dispón a emprender o camiño de retorno, comezan a sucederse marabillas e feitos insólitos que, dalgún modo, son exemplo de distintas ameazas que podían acosar a todo aventureiro no seu camiño: unha vez que ía marchar de Xerusalén esquecendo o encargo, este élle lembrado por unha voz do ceo. O monxe-romeu decide entón ir mercar a máis fermosa das imaxes, deixando a aqueles que o acompañaban; xa coa imaxe de María no seu haber, emprende o camiño de regreso só -e, en consecuencia, ficando máis vulnerable aos perigos-. Acontece entón que se cruza cun animal tipicamente salvaxe, concretamente un león, pero a besta pasa con omildança -isto é, mansamente, e non con felonia- por graza divina. Pero, continúa a narración, aínda non perdera medo do león, encontrouse de novo en perigo mortal a causa dun ladrón con vontade de matalo e dividir o botín coa súa cuadrilla; outra vez auxiliado pola voz celestial, decidiu levar a imaxe consigo a Constantinopla e embarcou nun navío. Durante a travesía, xurdiu unha tormenta que obrigou ás xentes a deitar no mar boa parte das súas pertenzas, mentres que el agarraba con desasperança (v. 126) a imaxe da Virxe;

${ }^{39}$ Tamén segundo o relato de Berceo deste milagre: «la prennada mesquina, cargada de rrencura, / fincó entre las ondas en fiera angostura» (Gonzalo de Berceo, Milagros de Nuestra Señora, Juan Carlos Bayo e Ian Michael (eds.), Madrid, Castalia, 2006, p. 220; corresponde aos versos 439cd desa edición). 
a voz celestial ditou ao monxe non desfacerse da imaxe, obrándose así un novo milagre e facéndose explícito un estado emocional oposto do anterior, sobresaíndo a alegría e a sensación de amparo.

Por no mar deita-la. | Que a non deitasse

hũa voz lle disse, | ca era peccado, mas contra o ceo | suso a alçasse, e o tempo forte $\mid$ seria quedado.

Diz: «Prestes estamos.»

Enton a ergia

e diz con fiança:

«A ti graças damos

que es alegria

noss' e amparança.»

Por que nos ajamos...

E log' a tormenta | quedou essa ora, e a nav' a Acre | enton foi tornada; e con ssa omagen $\mid$ o monge foi fora e foi-sse a casa $\mid$ da dona onrrada. (CSM9: 131-145).

Máis particular aínda é a experiencia da Emperatriz do coñecidísimo milagro da CSM5, que despois de sucesivas desgrazas foi castigada a ser afundida no mar. Unha voz do ceo diríxese en ton ameazante contra os mariñeiros, que optan por deixar vivir a Emperatriz, abandonándoa nunha pena, dando conta de que esta medida se entendía como unha morte segura e non exenta de angustia e de sufrimento:

Os marỹeiros disseron enton: «Pois est' a Deus non praz, leixemo-la sobr' aquesta pena, u pod' aver assaz de coita e d'affan e pois morte, u outra ren non jaz, ca, se o non fezermos, en mal ponto vimos seu solaz.

E pois foy feyto, o mar nona leixou en paz, ante a vẽo con grandes ondas combater.

Que nas coitas deste mundo ben quiser soffrer..

A Emperadriz, que non vos era de coraçon rafez, com' aquela que tanto mal sofrera e non hũa vez, tornou, con coita do mar e de fame, negra come pez; mas en dormindo a Madre de Deus direi-vos que lle fez: tolleu-ll' a fam' e deu-ll' hũa erva de tal prez, con que podesse os gaffos todos guarecer.

Que nas coitas deste mundo ben quiser soffrer... (CSM5: 117-130). 
Esta pasaxe en que a Emperatriz é abandonada no medio do mar pode ser vista á luz de certas explicacións de Villain-Gandossi:

A aquel de quien uno se quiere desembarazar, se le entrega indefenso a las olas. Se tiene así el sentimiento reconfortante de no haberlo matado de manera concreta, de dejar a Dios la decisión de salvarlo. El adiós a la orilla del mar es a la vez la más desgarradora y la más literaria de las despedidas. Siempre dispuesto a engullir, a devorar, este mar incierto, móvil, lleno de monstruos y de misterios, sometido a los caprichos del aire, es para el héroe un enemigo sin rostro, un adversario mítico sobre el que debe triunfar para asumir su destino ${ }^{40}$.

\section{CONCLUSIÓNS}

Malia non ser máis que unha aproximación centrada nunha serie de cantigas que incorporan travesías ambientadas no mar, esta incursión permite confirmar que as Cantigas de Santa Maria de Alfonso X son un marco máis que propicio para que se narren viaxes con distintos niveis de significación ${ }^{41}$. Nelas irrompe sempre o extraordinario, xa non só como risco para aquel que comezou unha aventura, senón que ademais -e o máis importante- se incorpora o marabilloso para auxilio, esperanza, amparo, conforto e salvación do viaxeiro.

Navegan personaxes de diferentes condicións e impulsados por distintas vontades, pero a incondicional intervención de María deixa nun segundo plano as diferenzas que inicialmente poderían fixarse entre eles. A vivencia da marabilla acabará por transformalos a todos de maneira semellante, e de tal modo fican reducidos ao rol de devotos tocados espiritualmente no transcurso do seu itinerario. María defínese como a única capaz de impedir o inevitable, á diferenza doutros santos, xa que ela, como Nai do Creador dos catro elementos, ten poder para gobernar sobre as distintas forzas da natureza como mareas, tormentas e ventos ${ }^{42}$. O mar aparece na obra mariana como un medio perigoso, indómito, incontrolable para o home, pois para unha parte da tradición cristiá o mar é metáfora da inmensidade e da potencia do seu creador $^{43}$. As forzas limitadas do ser humano non tiñan ningún efecto sobre esa inmensidade e ren non lles valia siso nen cordura, como ben se recoñece na CSM36. Na obra, fica

\footnotetext{
${ }^{40}$ Christiane Villain-Gandossi, «En la Edad Media,...», art. cit., p. 75.

${ }^{41}$ Como sinalaba D. Grégorio: «Tout déplacement physique peut devenir une sorte de pèlerinage puisqu'il est l'occasion de contempler une manifestation miraculeuse» («Pèlerinages et chemin initiatique...», art. cit., p. 134).

${ }^{42}$ Como explicitamente repite o refrán da CSM33: «Gran poder á de mandar / o mar e todolos ventos / a Madre daquel que fez / todo-los quatr' elementos» (CSM33: refrán).

${ }^{43}$ Saverio Guida e Fortunata Latella, «Il mare come dimensione metaforica nella letteratura italiana del Due e Trecento», A. Fassó, L. Formisano e M. Mancini (eds.), Filologia romanza e cultura medievale. Studi in honore di Elio Melli, Alessandria, Edizioni dell'Orso, 1998, vol. I, pp. 363-385.
} 
manifesta a impotencia das xentes do medievo para se valeren por si soas ante os perigos mariños. Repítense as situacións de angustia e medo provocadas por fenómenos como as tormentas ou os vendavais no transcurso dunha travesía, situacións nas que só o poder divino pode devolver a calma. Ademais, nalgunhas narracións, o motivo da tormenta e do vendaval no mar pode incorporarse como castigo daqueles que se definen como ameaza dos navegantes-devotos (así, nos milagres 35 e 379 ).

Desde a exposición do perigo ata a vivencia do milagre e a realización do cambio, ábrese un abano de emocións que abrangue desde o medo e a angustia -utilizándose expresións diversas como pavor, medo, coita, tormenta e tempestade (estes últimos no seu valor metafórico)-, ata a tranquilidade e alegría que comporta o reequilibrio da situación, para o que foron empregadas non só expresións que no seu sentido recto remiten ao pracer e á ledicia, senón tamén outras metafóricas, en descricións destinadas a confeccionar un lugar caracterizado por un novo estado de graza. 
$\cos$

\title{
PERIGOS E MEDOS NAS CANTIGAS DE SANTA MARIA. DO MAR E DOS SEUS TORMENTOS
}

\begin{abstract}
Resumo: Nas Cantigas de Santa Maria de Alfonso X, a sociedade medieval aparece representada dun modo máis ou menos realista. Textos e imaxes dan conta da mobilidade característica dos distintos grupos sociais que aparecen retratados nesta colección. Ademais, estas viaxes adoitan presentarse en estreita relación ao marabilloso, de tal modo que se presentan como unha aventura transformadora, non exenta de risco e emocións. Este traballo céntrase naquelas narracións das Cantigas de Santa Maria que incorporan unha travesía por mar, que normalmente aparece descrito como un medio indómito e perigoso para os homes, atendendo ás emocións que se desencadenan neses episodios de perigo mariño.
\end{abstract}

Palabras Chave: Cantigas de Santa Maria, Lírica galego-portuguesa, emocións, medo, coita, perigos do mar.

\section{DANGER AND FEAR IN THE CANTIGAS DE SANTA MARIA. DO MAR E DOS SEUS TORMENTOS}

\begin{abstract}
In the Cantigas de Santa Maria of Alfonso X, the medieval society is represented in a realistic manner. Into the collection, texts and images show the movement of different social groups. In addition, their travels involved marvels and miracles, so they were transforming adventures with risks and emotions. This paper aims to explore some narratives of the Cantigas de Santa Maria that include a journey across the sea, which is usually described as a wild and unsafe environment for medieval people, paying attention to the emotions that are triggered in those episodes of danger.
\end{abstract}

Keywords: Cantigas de Santa Maria, Galician-Portuguese lyric, emotions, fear, coita (anxiety), dangers of the sea. 